\title{
Outcomes of Kawasaki Disease in Families
}

\author{
Toshimasa Nakada
}

\section{ABSTRACT}

An epidemiological study showed that a positive family history of Kawasaki disease (KD) was a risk factor for intravenous immunoglobulin (IVIG) therapy resistance, coronary artery lesions (CALs), and KD recurrence. However, real-world outcomes of KD patients with a family history remain unclear. The objective of this study was to elucidate the outcomes of KD patients with a family history in the era of $2 \mathrm{~g} / \mathrm{kg}$ IVIG therapy. This retrospective study included data from $201 \mathrm{KD}$ patients who underwent acute-phase treatment from January 2009 to June 2020, with $184(91.5 \%)$ receiving $2 \mathrm{~g} / \mathrm{kg}$ IVIG therapy. The patients were divided into 13 (family group) with and 188 (nonfamily group) without a family history of KD. The rates of IVIG resistance $(8.3 \%$ vs. $22.1 \%, P=0.315)$, rescue therapy $(8.3 \%$ vs. $12.8 \%, P=1.000)$, CALs $(0.0 \%$ vs. $2.7 \%, P=1.000)$, and KD recurrence $(0.0 \%$ vs. $3.2 \%, P=1.000)$ were similar between the family and nonfamily groups.

Keywords: Family, Intravenous immunoglobulin therapy, Kawasaki disease, Outcomes.

\section{INTRODUCTION}

Kawasaki disease (KD) is a pediatric systemic vasculitis of unknown etiology for which a genetic influence is suspected [1]. One study showed that the inositol 1, 4, 5triphosphate 3-kinase $\mathrm{C}$ gene is associated significantly with $\mathrm{KD}$ susceptibility and an increased risk of coronary artery lesions (CALs) [1]. Several evidences suggest the importance of genetic factors in disease susceptibility and outcome [1]. The incidence of KD is 10 to 20 times higher in Japan than in Western countries [2]. Compared with the general populations, the risk of KD in siblings of affected children is 10 times higher and the incidence in children born to parents with a history of $\mathrm{KD}$ is twice as high [3], [4]. Familial aggregation of the disease also has been observed [5].

An epidemiological study showed that a positive family history of KD was a risk factor for intravenous immunoglobulin (IVIG) therapy resistance, CAL development, and KD recurrence [6]. However, real-world outcomes of KD patients with a family history remain unclear. The objective of this study was to elucidate the outcomes of KD patients with a positive family history in the era of $2 \mathrm{~g} / \mathrm{kg}$ IVIG therapy.

\section{PARTICIPANTS AND MethodS}

Our institutional ethics committee approved the study protocol and waived the requirement of patient consent due to the retrospective nature of the study.

This retrospective study included data from 215 patients who underwent acute-phase treatment for $\mathrm{KD}$ between January 2009 and June 2020 (Fig. 1). KD was diagnosed based on the criteria (Japanese, fifth edition) mentioned in the diagnostic guidelines for KD until August 2019 and on the revised criteria (Japanese, sixth edition) from September 2019 [7], [8].

Patients with the first episode of KD were included. A total of 14 patients with complications before initial therapy or with follow-up periods of $<2$ months were excluded (Fig. 1). Those excluded patients had no family history of KD.

The remaining patients were divided into two groups: those with (family group, $\mathrm{n}=13$ ) and those without (nonfamily group, $\mathrm{n}=188$ ) a family history of KD (Fig. 1). The outcomes were the rates of IVIG resistance, rescue therapy, CALs, and KD recurrence.

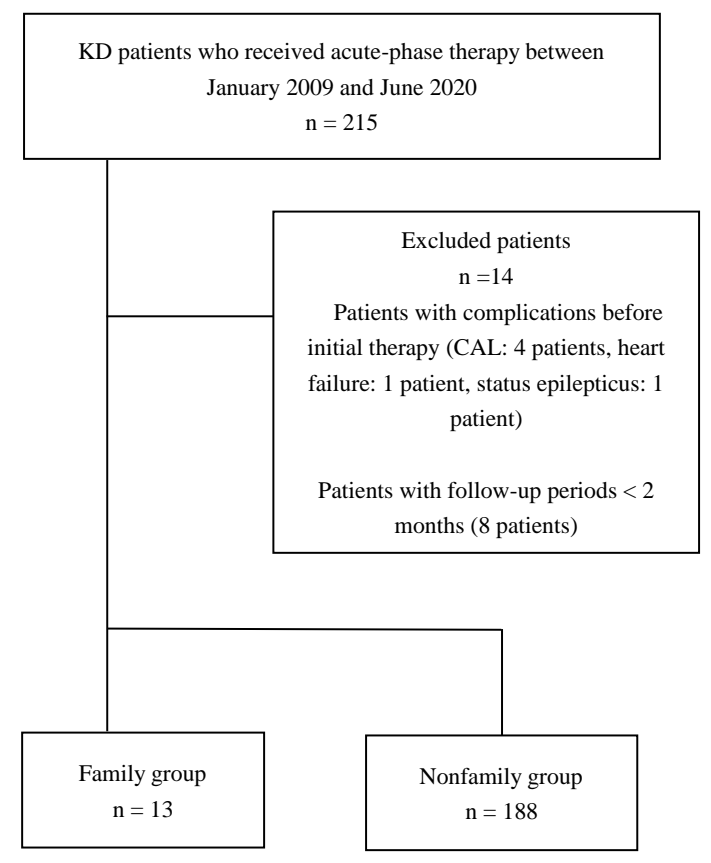

Fig. 1. Study profile.

KD: Kawasaki disease, CAL: coronary artery lesion. 
A positive family history of $\mathrm{KD}$ was defined as $\mathrm{KD}$ in siblings or in children born to parents with a history of KD. IVIG resistance was defined as a fever that persisted or recurred $24 \mathrm{~h}$ after initial treatment [9]. KD presentation was defined as relapse when a second episode occurred within 2 months of the first episode after initial defervescence [10], [11]. Defervescence was defined as a body temperature < $37.5^{\circ} \mathrm{C}$ for at least $24 \mathrm{~h}$, and the defervescence time was the moment when the body temperature reached $<37.5{ }^{\circ} \mathrm{C}$. Recurrent KD was defined as a secondary presentation of another episode 2 months after an initial episode [10], [11].

\section{A. Initial Therapy}

During the study period, an initial single IVIG infusion of $2 \mathrm{~g} / \mathrm{kg} / \mathrm{dose}$, starting on day 5 of the illness, was given as initial therapy, whenever possible [12]. Patients without inflammation or complications at presentation received acute-phase therapy without IVIG [12]. Between January 2009 and November 2017, anti-inflammatory drugs (aspirin or flurbiprofen) were initiated within $24 \mathrm{~h}$ after the initial IVIG infusion ended [13]. Aspirin and flurbiprofen were begun at 30 and $3-5 \mathrm{mg} / \mathrm{kg} /$ day, respectively, and decreased to $5-10$ and $3 \mathrm{mg} / \mathrm{kg} / \mathrm{day}$, respectively, once the patient was afebrile [13]. Each treating physician chose aspirin or flurbiprofen after considering the patient's liver function and the risk of Reye syndrome during the influenza season. After December 2017, low-dose aspirin (5 mg/kg/day) was begun on days 8 to 10 of illness after completion of IVIG infusion, including the second course of therapy [12].

\section{B. Rescue Therapy}

The decision to use rescue therapies in resistant patients was made 48 to $72 \mathrm{~h}$ after completion of the initial IVIG therapy. The decision was made comprehensively according to clinical parameters, including body temperature, major KD symptoms, general condition, and laboratory data [12]. Course 2 of therapy comprised rescue IVIG therapy at $2 \mathrm{~g} / \mathrm{kg} / \mathrm{dose}$, and course 3 was an ulinastatin infusion, the third course of IVIG therapy, or plasma exchange [12].

\section{Diagnosis of CAL}

CALs were diagnosed using echocardiography based on the Japanese criteria reported by Kobayashi et al [14]. A CAL was diagnosed if any examination showed an internal lumen diameter of $\geq 3 \mathrm{~mm}$ in a patient younger than 5 years or a diameter of $\geq 4 \mathrm{~mm}$ in a patient older than 5 years if the internal diameter of a segment was at least 1.5 times that of an adjacent segment or if the lumen appeared irregular. A transient CAL was defined as the disappearance of a CAL within 30 days of the illness.

\section{Statistical Analysis}

Statistical analyses were conducted using Stat Flex Version 6 for Windows (Artech Co., Ltd., Osaka, Japan). Chi-square, Fisher's exact, and Mann-Whitney U tests were used as appropriate, with sample size considerations. P < 0.05 was considered statistically significant.

\section{RESULTS}

The family group included 13 patients $(10$ siblings and three children born to parents with a history of KD) (Tables
I, II, and III). Of the five sibling pairs, the older sibling presented with KD first in three pairs and four pairs had intervals of KD onset between the first and second sibling of $>1$ year (Table I). No patient in the family group had incomplete KD (Tables I and III).

Of the 13 patients in the family group, 12 received 2 $\mathrm{g} / \mathrm{kg} /$ dose IVIG therapy on day 5 or 6 of illness, and 11 of them $(91.7 \%)$ responded (Tables II and III). No patient in the family group had CAL at $<1$ and 1 month after KD onset (Tables II and III). During a median follow-up of 4 years and 5 months (range: 3 months -6 years and 1 month) after KD onset, no patient in the family group had recurrent $\mathrm{KD}$.

The rates of IVIG resistance ( $8.3 \%$ vs. $22.1 \%, \mathrm{P}=0.315)$, rescue therapy ( $8.3 \%$ vs. $12.8 \%, \mathrm{P}=1.000)$, CALs $(0.0 \%$ vs. $2.7 \%, \mathrm{P}=1.000)$, and $\mathrm{KD}$ recurrence $(0.0 \%$ vs. $3.2 \%, \mathrm{P}=$ 1.000 ) were similar between the two groups (Table IV).

TABLE I: BASELINE CHARACTERISTICS OF SIBLING WITH KAWASAKI DISEASE

\begin{tabular}{|c|c|c|c|c|c|}
\hline $\mathrm{Pt}$ & Gender & Age & Siblings & Interval & $\begin{array}{c}\text { Major } \\
\text { signs }\end{array}$ \\
\hline $\begin{array}{c}\text { Siblings } 1 \\
\text { First onset pt }\end{array}$ & Male & $9 \mathrm{~m}$ & Older & $\begin{array}{c}6 \mathrm{y} \text { and } \\
0 \mathrm{~m}\end{array}$ & 5 \\
\hline $\begin{array}{c}\text { Siblings } 1 \\
\text { Second onset pt }\end{array}$ & Female & $\begin{array}{c}2 \mathrm{y} \text { and } \\
0 \mathrm{~m}\end{array}$ & Younger & $\begin{array}{l}6 \mathrm{y} \text { and } \\
0 \mathrm{~m}\end{array}$ & 6 \\
\hline $\begin{array}{c}\text { Siblings } 2 \\
\text { First onset pt }\end{array}$ & Male & $\begin{array}{c}4 \mathrm{y} \text { and } \\
9 \mathrm{~m}\end{array}$ & Older & $\begin{array}{c}6 \mathrm{y} \text { and } \\
3 \mathrm{~m}\end{array}$ & 5 \\
\hline $\begin{array}{c}\text { Siblings } 2 \\
\text { Second onset pt }\end{array}$ & Female & $\begin{array}{c}2 \mathrm{y} \text { and } \\
8 \mathrm{~m}\end{array}$ & Younger & $\begin{array}{l}6 \mathrm{y} \text { and } \\
3 \mathrm{~m}\end{array}$ & 6 \\
\hline $\begin{array}{c}\text { Siblings } 3 \\
\text { First onset pt }\end{array}$ & Male & $\begin{array}{c}2 \mathrm{y} \text { and } \\
10 \mathrm{~m}\end{array}$ & Younger & 7 days & 6 \\
\hline $\begin{array}{c}\text { Siblings } 3 \\
\text { Second onset pt }\end{array}$ & Female & $\begin{array}{c}4 \mathrm{y} \text { and } \\
0 \mathrm{~m}\end{array}$ & Older & 7 days & 6 \\
\hline $\begin{array}{c}\text { Siblings } 4 \\
\text { First onset pt }\end{array}$ & Female & $\begin{array}{c}4 \mathrm{y} \text { and } \\
2 \mathrm{~m}\end{array}$ & Younger & $\begin{array}{l}1 \mathrm{y} \text { and } \\
8 \mathrm{~m}\end{array}$ & 6 \\
\hline $\begin{array}{c}\text { Siblings } 4 \\
\text { Second onset pt }\end{array}$ & Female & $4 \mathrm{~m}$ & Older & $\begin{array}{l}1 \mathrm{y} \text { and } \\
8 \mathrm{~m}\end{array}$ & 5 \\
\hline $\begin{array}{l}\text { Siblings } 5 \\
\text { First onset pt }\end{array}$ & Female & $\begin{array}{c}2 \mathrm{y} \text { and } \\
6 \mathrm{~m}\end{array}$ & Older & $\begin{array}{l}6 \mathrm{y} \text { and } \\
5 \mathrm{~m}\end{array}$ & 5 \\
\hline $\begin{array}{c}\text { Siblings } 5 \\
\text { Second onset pt }\end{array}$ & Male & $\begin{array}{c}4 \mathrm{y} \text { and } \\
5 \mathrm{~m}\end{array}$ & Younger & $\begin{array}{l}6 \mathrm{y} \text { and } \\
5 \mathrm{~m}\end{array}$ & 6 \\
\hline
\end{tabular}

Pt: patient, KD: Kawasaki disease, Age: age at KD onset, y: years, m: months, Interval: interval period of $\mathrm{KD}$ onset between the first and the second patient, Major signs: number of KD major signs.

TABLE II: TREATMENT AND OUTCOMES OF SIBLINGS WITH KAWASAKI DISEASE

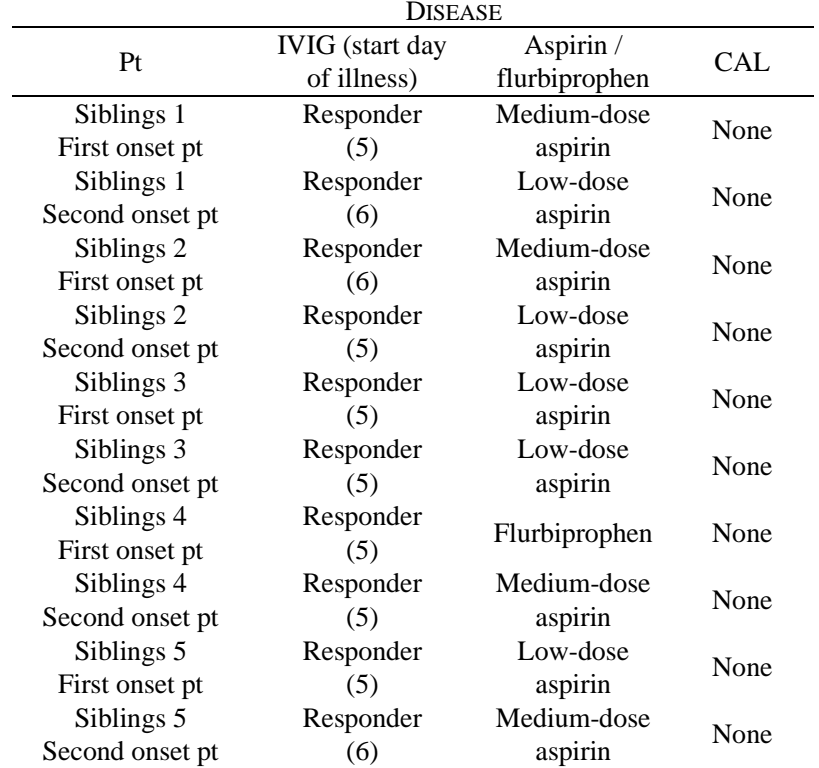

Pt: patient, IVIG: intravenous immunoglobulin therapy, CAL: coronary artery lesion. 
TABLE III: BASELINE CHARACTERISTICS OF PATIENTS WITH PARENTS ASSOCIATED WITH KAWASAKI DISEASE IN CHILDHOOD

\begin{tabular}{cccc}
\hline $\begin{array}{c}\text { Pt number } \\
\text { Gender }\end{array}$ & Female & $\begin{array}{c}12 \\
\text { Female }\end{array}$ & $\begin{array}{c}13 \\
\text { Female }\end{array}$ \\
\hline Age & 2 y and $10 \mathrm{~m}$ & $3 \mathrm{y}$ and $7 \mathrm{~m}$ & $2 \mathrm{y}$ and $0 \mathrm{~m}$ \\
$\begin{array}{c}\text { Parents with } \\
\text { KD }\end{array}$ & Father & Mother & Mother \\
Major signs & 6 & 5 & 5 \\
IVIG (start day & Non-responder & Responder (6) & Responder (5) \\
of illness) & $(5)$ & None & None \\
CAL & None &
\end{tabular}

Pt: patient, KD: Kawasaki disease, Age: age at KD onset, y: years, m: months, Major signs: number of KD major signs, IVIG: intravenous immunoglobulin therapy, CAL: coronary artery lesion.

TABLE IV: COMPARISON OF CLINICAL FINDINGS BETWEEN FAMILY GROUP AND NONFAMILY GROUP

\begin{tabular}{|c|c|c|c|}
\hline Variables & $\begin{array}{l}\text { Family group } \\
\qquad(\mathrm{n}=13)\end{array}$ & $\begin{array}{c}\text { Non-family } \\
\text { group } \\
(\mathrm{n}=188)\end{array}$ & P-value \\
\hline Male gender & $4(30.8 \%)$ & $95(50.5 \%)$ & 0.168 \\
\hline $\begin{array}{c}\text { Age at KD } \\
\text { onset (months) }\end{array}$ & $32.0(20.3-48.5)$ & $26.0(14.0-45.5)$ & 0.792 \\
\hline $\begin{array}{c}\text { Incomplete type } \\
\text { Low-dose }\end{array}$ & $0(0.0 \%)$ & $39(20.7 \%)$ & 0.077 \\
\hline $\begin{array}{c}\text { aspirin / } \\
\text { medium-dose } \\
\text { aspirin / } \\
\text { flurbiprofen }\end{array}$ & $\begin{array}{c}5(38.5 \%) / \\
7(53.8 \%) / \\
1(7.7 \%)\end{array}$ & $\begin{array}{c}35(18.6 \%) / \\
89(47.3 \%) / \\
64(30.4 \%)\end{array}$ & 0.077 \\
\hline IVIG & $12(92.3 \%)$ & $172(91.5 \%)$ & 1.000 \\
\hline $\begin{array}{c}\text { Day of illness at } \\
\text { initial IVIG } \\
\text { therapy }\end{array}$ & $5.0(5.0-6.0)$ & $5.0(5.0-6.0)$ & 0.453 \\
\hline Non-responder & $1(8.3 \%)$ & $38(22.1 \%)$ & 0.315 \\
\hline Rescue therapy & $1(8.3 \%)$ & $22(12.8 \%)$ & 1.000 \\
\hline $\begin{array}{l}\text { For non- } \\
\text { responder }\end{array}$ & $1(8.3 \%)$ & $16(9.3 \%)$ & 1.000 \\
\hline For relapse & $0(0.0 \%)$ & $5(2.9 \%)$ & 1.000 \\
\hline For responder & $0(0.0 \%)$ & $1(0.6 \%)$ & 1.000 \\
\hline CAL & $0(0.0 \%)$ & $5(2.7 \%)$ & 1.000 \\
\hline $\begin{array}{l}\text { Less than one } \\
\text { month after KD } \\
\text { onset }\end{array}$ & $0(0.0 \%)$ & $5(2.7 \%)$ & 1.000 \\
\hline $\begin{array}{l}\text { One month after } \\
\text { KD onset }\end{array}$ & $0(0.0 \%)$ & $2(1.1 \%)$ & 1.000 \\
\hline Recurrence & $0(0.0 \%)$ & $6(3.2 \%)$ & 1.000 \\
\hline $\begin{array}{l}\text { Follow-up } \\
\text { periods } \\
\text { (months) }\end{array}$ & $53(11.3-62.5)$ & $41.0(14.0-61.5)$ & 0.853 \\
\hline
\end{tabular}

Data are presents as $\mathrm{n}(\%)$ or median (interquartile range)/

Incomplete type: major signs of $\mathrm{KD} \leq 4, \mathrm{KD}$ : Kawasaki disease, IVIG: intravenous immunoglobulin therapy, CAL: coronary artery lesion.

\section{DISCUSSION}

The main findings of this study were that the rates of IVIG resistance, rescue therapy, CALs, and KD recurrence were similar between the family and nonfamily groups (Table IV). These findings suggested that a positive family history of KD is not a risk factor for IVIG therapy resistance, CAL development, and $\mathrm{KD}$ recurrence in the era of $2 \mathrm{~g} / \mathrm{kg}$ IVIG therapy.

One study using multivariable Cox regression analysis identified a positive family history as independently associated with major cardiac events in patients with dilated cardiomyopathy [15]. However, real-world outcomes of KD patients with a family history remain unclear in the era of 2 $\mathrm{g} / \mathrm{kg}$ IVIG therapy. One Japanese epidemiological study showed that a positive family history of $\mathrm{KD}$ was a risk factor for IVIG therapy resistance, CAL development, and KD recurrence [6]. This was a cross-sectional study using data from nationwide surveys of KD patients between 1999 and 2002 [6]. Furthermore, one study of KD siblings in North America conducted between 1997 and 2003 demonstrated higher rates of KD recurrence $(20.0 \%)$, IVIG retreatment (45.5\%), and CAL development (20.0\%) [5].

The mainstay of current standard therapy in the acutephase of $\mathrm{KD}$ is $2 \mathrm{~g} / \mathrm{kg}$ IVIG and the evidence regarding CAL suppression of $2 \mathrm{~g} / \mathrm{kg}$ IVIG therapy has been established [9]. Of the 201 patients, 184 (91.5\%) received 2 $\mathrm{g} / \mathrm{kg}$ IVIG therapy in the present study (Table IV). Conversely, $2 \mathrm{~g} / \mathrm{kg}$ IVIG was not widespread as acute-phase standard therapy for KD in 1997-2003. This may be a reason for the different outcomes in $\mathrm{KD}$ patients with a positive family history between the previous study and the present study.

Addition of medium or high-dose aspirin to $2 \mathrm{~g} / \mathrm{kg}$ IVIG therapy presently is controversial [16]. A randomized controlled trial on the effectiveness of IVIG monotherapy and IVIG combined with high-dose aspirin in the acute KD stage is ongoing [17]. Studies suggested that aspirin may inhibit CAL prevention and that delayed use of aspirin (DUA) may be beneficial for the suppression of CALs and prevention of coronary artery stenosis in patients with KD [13], [18]-[20]. Furthermore, a recent study showed favorable medium-term outcomes of CALs in KD patients who received $2 \mathrm{~g} / \mathrm{kg}$ IVIG with DUA [12]. The incidence of $\mathrm{KD}$ recurrence is high among those with cardiac sequelae during the initial episode [10]. The low rate of CALs during the first episode may be a factor for the lower rate of KD recurrence [12]. The use of $2 \mathrm{~g} / \mathrm{kg}$ IVIG therapy with DUA in the present study may be an additional reason for the favorable outcomes in KD patients with a positive family history of KD.

Siblings may have incomplete or atypical KD, which may go unnoticed, and these children may suffer CAL despite normal initial echocardiography [21]-[24]. Incomplete KD or atypical KD may lead to delay in diagnosis and treatment. This is a risk factor for CAL development. Fortunately, no patient in the family group, including siblings, had incomplete $\mathrm{KD}$ or atypical KD and received delayed initial IVIG therapy (Tables I, II, and III). The prevalence of CALs in patients receiving IVIG therapy on day 7 of illness was significantly higher than that in patients receiving the therapy before day $7(\mathrm{P}=0.024)$ [25]. A total of 12 family group patients received initial IVIG therapy between days 5 and 6 of illness (Tables II and III). This may be another reason for the favorable outcomes in our family group patients.

The epidemiological study regarding KD patients from 1999 to 2000 showed that the prevalence of KD recurrence and incidence involving siblings of patients whose parents had a history of the disease were five or six times higher than those of all patients [4]. In the present study, three patients whose parents had a history of KD did not have either KD recurrence or siblings with $\mathrm{KD}$. The mentioned study also showed a high probability of the positive past history of KD among parents with KD children [4]. However, the parents of the KD siblings did not have a history of $\mathrm{KD}$ in the present study. Further studies are warranted to elucidate the risk and clinical features regarding KD in families in the era of $2 \mathrm{~g} / \mathrm{kg}$ IVIG therapy. 
A nationwide epidemiological survey of $\mathrm{KD}$ in Japan (2015-2016) showed that 661 of 31,595 patients (2.1\%) had $\geq 1$ sibling affected by KD and $368(1.2 \%)$ had a parent with a history of KD [26]. In the present study of $215 \mathrm{KD}$ patients, the rates of KD siblings and parents with a history of $\mathrm{KD}$ were $4.7 \%$ and $1.4 \%$, respectively. The higher rate of siblings may be due to bias based on the small sample size of this study.

One study showed that only two $(22.2 \%)$ of the nine sibling pairs had onset of disease within 1 month of each other, whereas in six pairs, the onset of disease was separated by at least 1 year [5]. This finding was consistent with that in the present study: only one (20.0\%) of the five sibling pairs had onset of disease within 1 month of each other, whereas in four pairs, the onset of disease was separated by at least 1 year (Table I). An epidemiological study suggested that genetic mechanism and several infectious agents are involved in KD [26]. The extraordinarily high incidence of the disease and short interval between onsets in twins suggests an increased likelihood of common exposure of twins to an infectious agent and also the possibility of a genetically determined susceptibility factor [3].

Infections are considered to be a trigger for $\mathrm{KD}$, especially in genetically susceptible hosts [27]. KD occurring within a short interval among sibling children is an essential clinical observation supporting this hypothesis [27]. However, of the $>201$ sibling pairs reviewed, a specific infectious trigger was documented in only five pairs, which included streptococcus, adenovirus, parvovirus, varicellazoster virus, and measles virus [27]-[29]. In the present study, a specific infectious trigger was not documented in sibling pair number 3 with a 7-day interval (Table I). The siblings are likely to have similar genetic backgrounds and exposure to environmental risk factors [27]. Analysis of tropospheric winds transporting infectious or toxic agents in relation to the occurrence of $\mathrm{KD}$ reveals a probable incubation period of 6 to $48 \mathrm{~h}$, thereby reflecting a host response to the antigen or toxin rather than an infection per se [30]. In such circumstances, KD probably would occur simultaneously in siblings [27].

One study showed that the older sibling often presented with KD first and that this probably is a reflection of a greater likelihood of exposure to an infectious trigger [27]. This could be a result of the older sibling becoming infected at school/daycare and passing on the putative infectious agent to the younger sibling at home [27]. Of the five sibling pairs, the older sibling presented with KD first in the three pairs in the present study, whereas a specific infectious trigger was not documented (Table I).

The limitations of this study include the small sample size and the retrospective study design.

In conclusion, the rates of IVIG resistance, rescue therapy, CALs, and KD recurrence were similar between the family and nonfamily groups. These findings suggested that a positive family history of $\mathrm{KD}$ is not a risk factor for IVIG therapy resistance, CAL development, and KD recurrence, and that further studies are warranted to elucidate the risk of $\mathrm{KD}$ in families in the era of $2 \mathrm{~g} / \mathrm{kg}$ IVIG therapy.

\section{ACKNOWLEDGMENT}

I would like to thank all of those who were involved in the medical management of the patients included in this study, and Enago (www.enago.jp) for the English language review.

\section{REFERENCES}

[1] Onouchi Y, Gunji T, Burns JC, Shimizu C, Newburger JW, Yashiro $\mathrm{M}$, et al. ITPKC functional polymorphism associated with Kawasaki disease susceptibility and formation of coronary artery aneurysms. Nat Genet. 2008 January; 40 (1): 35-42. doi:10.1038/ng.2007.59.

[2] Cook DH, Antia A, Attie F, Gersony WM, Kamiya T, Kato H, et al. Results from an international survey of Kawasaki disease in 1979-82. Can J Cardiol 1989; 5: 389-94. [PubMed: 2605549].

[3] Fujita Y, Nakamura Y, Sakata K, Hara N, Kobayashi M, Nagai M, et al. Kawasaki disease in families. Pediatrics 1989; 84: 666-9. [PubMed: 2780128].

[4] Uehara R, Yashiro M, Nakamura Y, Yanagawa H. Kawasaki disease in parents and children. Acta Paediatr 2003; 92: 694-7. [PubMed: 12856980] doi: 10.1080/08035320310002768.

[5] Dergun M, Kao A, Hauger SB, Newburger JW, Burns JC. Familial occurrence of Kawasaki syndrome in North America. Arch Pediatr Adolesc Med 2005; 159: 876-81. doi:10.1001/archpedi.159.9.876. [PubMed: 16143748].

[6] Uehara R, Yashiro M, Nakamura Y, Yanagawa H. Clinical features of patients with Kawasaki disease whose parents had the same disease. Arch Pediatr Adolesc Med 2004; 158 (12): 1166-9. doi: 10.1001/archpadi.158.12.1166.

[7] Ayusawa M, Sonobe T, Uemura S, Ogawa S, Nakamura Y, Kiyosawa $\mathrm{N}$, et al. Revision of diagnostic guidelines for Kawasaki disease (the 5th revised edition). Pediatr Int 2005; 47: 232-4. https://doi.org/10.1111/j.1442-200x.2005.02033.

[8] Fukazawa R, Kobayashi J, Ayusawa M, Hamada H, Miura M, Mitani Y, et al. JCS/JSCS 2020 Guideline on Diagnosis and Management of Cardiovascular Sequelae in Kawasaki Disease. Circ J 2020; 84: 13481407. doi:10.1253/circj.CJ-19-1094.

[9] Rearch Committee of the Japanese Society of Pediatric Cardiology; Cardiac Surgery Committee for Development of Guidelines for Medical Treatment of Acute Kawasaki Disease. Guidelines for medical treatment of acute Kawasaki disease: report of the Research Committee of the Japanese Society of Pediatric Cardiology and Cardiac Surgery (2012 revised version). Pediatr Int 2014; 56: 135-58. https://doi.org/10.1111/ped.12317.

[10] Hirata S, Nakamura Y, Yanagawa H. Incidence rate of recurrent Kawasaki disease and related risk factors: from the results of nationwide surveys of Kawasaki disease in Japan. Acta Paediatr. 2001; $\quad 90(1): \quad 40-4 . \quad$ https://doi.org/10.1111/j.16512227.2001.tb00253.x.

[11] Nakada T. Usefulness of an initial single intravenous immunoglobulin infusion with delayed use of aspirin against Kawasaki disease relapse: a single-center retrospective study. Journal of Advanced Research in Medicine $2019 ; \quad 6 \quad$ (1): $18-24$. https://doi.org/10.24321/2349.7181.201905.

[12] Nakada T. Acute Phase Treatment and Medium-Term Outcomes in Kawasaki Disease. European Journal of Medical and Health Sciences 2020; 2 (4), $\quad$ August: 1-7. doi: http://dx.doi.org/10.24018/ejmed.2020.2.4.419.

[13] Nakada T. Effects of anti-inflammatory drugs on intravenous immunoglobulin therapy in the acute phase of Kawasaki disease. Pediatr Cardiol 2015; 36: 335-9. DOI 10.1007/s00246-014-1010-7.

[14] Kobayashi T, Inoue Y, Takeuchi K, OkadaY, Tamura K, Tomomasa $\mathrm{T}$, et al. Prediction of intravenous immunoglobulin unresponsiveness in patients with Kawasaki disease. Circulation 2006; 113: 2606-12. http://www.circulationaha.org DOI:10.1161/CIRCULATIONAHA.105.592865.

[15] Marume K, Noguchi T, Tateishi E, Morita Y, Miura H, Nishimura K, et al. Prognosis and Clinical Characteristics of Dilated Cardiomyopathy With Family History via Pedigree Analysis. Circ J 2020; 84: 1284-93. doi:10.1253/circj.CJ-19-1176.

[16] McCrindle BW, Tierney ESS. Acute treatment for Kawasaki disease: challenges for current and future therapies. J Pediatr 2017; 184: 7-10. DOI: 10.1016/j.jpeds.2017.01.072.

[17] Kuo HC, Guo MM, Lo MH, Hsieh KS, Huang YH. Effectiveness of intravenous immunoglobulin alone and intravenous immunoglobulin combined with high-dose aspirin in the acute stage of Kawasaki disease: study protocol for a randomized controlled trial. BMC Pediatr. 2018; 18: 200. https://doi.org/10.1186/s12887-018-1180-1. 
[18] Lau AC, Duong TT, Ito S, Yeung RS. Intravenous immunoglobulin and salicylate differentially modulate pathogenic processes leading to vascular damage in a model of Kawasaki disease. Arthritis Rheum 2009; 60: 2131-41. https://doi.org/10.1002/art.24660.

[19] Cho HJ, Bak SY, Kim SY, Yoo R, Baek HS, Yang S, et al. High neutrophil: lymphocyte ratio is associated with refractory Kawasaki disease. Pediatr Int 2017; 59: 669-74. https://doi.org/10.1111/ped.13240|.

[20] Nakada T. Acute phase treatment for prevention of coronary artery stenosis caused in Kawasaki disease: a single center retrospective study. Journal of Advanced Research in Medicine 2018; 5(4): 1-7. https://doi.org/10.24321/2349.7181.201818.

[21] Kottek A, Shimizu C, Burns JC. Kawasaki disease in monozygotic twins. Pediatr Infect Dis J 2011; 30(12):1114-6. doi:10.1097/INF.0b013e31822ac4ff.

[22] Zhang X, Sun J, Zhai S, Yang S. Kawasaki disease in two sets of monozygotic twins: is the etiology genetic or environmental? Pak J Med Sci 2013; 29(1):227-30.

[23] Fukuda S, Ito S, Fujiwara M, Abe J, Hanaoka N, Fujimoto T, Katsumori H. Simultaneous development of Kawasaki disease following acute human adenovirus infection in monozygotic twins: a case report. Pediatr Rheumatol Online J 2017; 15(1):39.

[24] Namita U, Saddiq MH, Ahamed Z. Simultaneous development of Kawasaki disease in identical twins: a case report. J Fam Med Prim Care 2019; 8(4):1481-2.

[25] Nakada T: Intravenous Immunoglobulin Therapy for Prevention of Coronary Artery Stenosis Caused in Kawasaki Disease. International Journal of Advances in Medical Sciences 2018; 3 (6): 1-13 www.kibanresearchpublications.com.

[26] Makino N, Nakamura Y, Yashiro M, Kosami K, Matsubara Y, Ae R, et al. Nationwide epidemiologic survey of Kawasaki disease in Japan, 2015-2016. Pediatr Int 2019; 61: 397-403. https://doi.org/10.1111/ped.13809.

[27] Banday AZ, Bhattacharya D, Pandiarajan V, Singh S. Kawasaki disease in siblings in close temporal proximity to each other-what are the implications? Clinical Rheumatology Pulished online: 10 August 2020 https://doi.org/10.1007/s10067-020-05328-5.

[28] Lee DH, Huang HP. Kawasaki disease associated with chickenpox: report of two sibling cases. Acta Paediatr Taiwan 2004; 45 (2): 94-6. [PMID: 15335119].

[29] Kuijpers TW, Herweijer TJ, Schölvinck L, Wertheim-Van Dillen PM, Van de Veer EM. Kawasaki disease associated with measles virus infection in a monozygotic twin. Pediatr Infect Dis J 2000;19(4):350-

[30] Rodó X, Curcoll R, Robinson M, Ballester J, Burns JC, Cayan DR, et al. Tropospheric winds from northeastern China carry the etiologic agent of Kawasaki disease from its source to Japan. Proc Natl Acad Sci USA 2014; 111(22):7952-7.

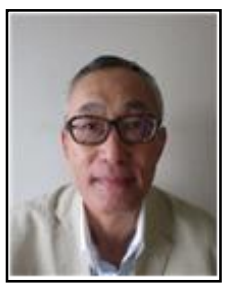

\section{Dr. T. Nakada}

Birth of place: Japan. Birth of date: 20/02/1957.

He received medical education at Hirosaki University School of Medicine. He had MD regarding pediatrics. He has been working as a pediatrician at Department of Pediatrics, Aomori Prefectural Central Hospital. Aomori City, Aomori Prefecture, Japan, from 1988 to the present time.

His major field of study is general pediatric cardiology: Kawasaki disease, arrhythmia, congenital heart disease, cardiomyopathy, heart disease screening, and preventive medicine. Acute phase treatment for Kawasaki disease using an initial single intravenous immunoglobulin therapy is one of his lifeworks.

Published articles

1. Nakada T. Acute phase treatment for infants younger than 1 year of age with Kawasaki disease: a single center retrospective study. Journal of Advanced Research in Medicine 2019; 6 (1): 1-6.

2. Nakada T. Risk stratification after initial therapy for intravenous immunoglobulin-resistant Kawasaki disease. Research Journal of Life Sciences, Bioinformatics, Pharmaceutical and Chemical Sciences 2019; 5 (5): $1-13$. 